\title{
Age-stratified distribution of metastatic sites in bladder cancer: A population-based analysis
}

\author{
Marco Bianchi, MD, ${ }^{* t}$ Florian Roghmann, MD, ${ }^{*} \pm$ Andreas Becker, MD,; Shyam Sukumar, MD; \\ Alberto Briganti, MD,, Mani Menon, MD,; Pierre I. Karakiewicz, MD, FRCSC, ${ }^{*}$ Maxine Sun, BSc,; \\ Joachim Noldus, MD; Quoc-Dien Trinh, MDE
}

\begin{abstract}
*Cancer Prognostics and Health Outcomes Unit, University of Montreal Health Centre, Montreal, QC; 'Department of Urology, Vita-Salute San Raffaele University, Milan, Italy; ${ }^{*}$ Department of Urology, University of Montreal Health Centre, Montreal, QC; ₹Vattikuti Urology Institute, Henry Ford Health System, Detroit, Ml; ${ }^{ \pm}$Department of Urology, Ruhr University Bochum, Marienhospital, Herne, Germany; §Martini-Clinic, Prostate Cancer Center, Hamburg-Eppendorf, Hamburg, Germany; 壮attikuti Urology Institute, Henry Ford Health System, Detroit, Ml; $€$ Department of Urology, Vita-Salute University, Urological Research Institute, Milan, Italy Dr. Bianchi and Dr. Roghmann equally contributed to this work.
\end{abstract}

Cite as: Can Urol Assoc J 2014;8(3-4):e148-58. http://dx.doi.org/10.5489/cuaj.787

Published online March 11, 2014.

\section{Abstract}

Introduction: Urothelial carcinoma of the urinary bladder (UCUB) is the most common malignancy of the urinary tract. We examined the distribution of site-specific metastases in patients with UCUB according to age and we assessed contemporary recommendations proposed by guidelines with regard to distant metastases.

Methods: Patients with metastatic UCUB (mUCUB) were abstracted from the Nationwide Inpatient Sample (1998-2007). Age was stratified into quartiles: $\leq 63,64-72,73-79$ and $\geq 80$ years. CochranArmitage trend test and multivariable logistic regression analysis tested the relationship between age and the rate of metastases. Finally, we identified patients at high risk of brain or bone metastases.

Results: Within 7543 patients with mUCUB, 25\%, 24\%, 23\%, $19 \%, 18 \%$ and $3 \%$ had lymph node, bone, urinary, lung and liver metastases, respectively. Overall, the rate of concomitant metastases was $29 \%$. The rate of multiple metastatic sites decreased with increasing age $(p<0.001)$. This was confirmed in patients with lung, bone, liver, urinary system and brain metastases (all $p \leq 0.04$ ). The rate of bone metastases was $15.0 \%$ in patients with exclusive abdominal metastases and $40.0 \%$ in patients with abdominal, thoracic and brain metastases. The rate of brain metastases was $1 \%$ in patients with exclusive abdominal metastases and $7 \%$ in patients with thoracic and bone metastases. Our findings are limited by the retrospective nature of the analyses.

Conclusions: We report a higher number of concomitant metastatic sites in young UCUB patients. Bone metastases are frequent in all patient groups, whereas brain metastases are common in UCUB patients with thoracic and/or bone metastases.

\section{Introduction}

Urothelial carcinoma of the urinary bladder (UCUB) is the most common malignancy of the urinary tract. In the United States, 69250 new cases of UCUB were diagnosed in 2011 and its incidence is increasing. ${ }^{1}$ Despite recent advances in the treatment of metastatic UCUB (mUCUB), ${ }^{2}$ about 15210 deaths from bladder cancer will occur in 2013. ${ }^{3}$ However, little is known on the metastatic distribution of bladder cancer.

In several cancers, diagnosis at an early age is associated with aggressive tumour dissemination. ${ }^{4-6}$ This association has previously been validated in renal cell carcinoma. ${ }^{7,8}$ It is possible that such tumours in younger patients are associated with more aggressive genomic alterations. ${ }^{9,10}$ However, these hypotheses have never been tested in the context of UCUB.

Based on these considerations, we examined the association between age and the distribution of metastatic sites in patients with UCUB. Specifically, we tested the hypothesis that younger age may be associated with a higher number of metastatic sites. Moreover, since patients with brain ${ }^{11}$ and bone ${ }^{12,13}$ metastases represent an unfavourable subset of individuals, we also assessed the rates of brain and bone metastases according to the distribution of other concomitant metastatic sites.

\section{Methods}

\section{Data source}

Data from 1998 to 2007 were abstracted from Nationwide Inpatient Sample (NIS). The NIS includes inpatient discharge data collected via federal-state partnerships, as part of the Agency for Healthcare Research and Quality's Healthcare 
Cost and Utilization Project. ${ }^{14,15}$ This study was exempt from institutional review board approval in accordance with provincial and federal legislation when dealing with populationbased publicly available data.

\section{Sample population}

Patients with a primary diagnosis of bladder cancer were identified using the International Classification of Disease, $9^{\text {th }}$ Revision, Clinical Modification (ICD-9-CM) diagnostic code: 188.0. Using secondary diagnostic codes, only patients with metastases were included in the study (Appendix 1).

For the purpose of the analysis, metastatic sites were categorized as (1) abdominal, which include small intestine, large intestine, liver, other metastasis in the digestive system, kidney, ovary, other metastasis in the urinary system, adrenal and abdominal lymph nodes (codes 196.2, 196.5 and 196.6) and (2) thoracic, which include lung, pleura, mediastinum, other metastases in the respiratory system and thoracic lymph nodes (codes 196.0, 196.1, 196.3). Brain and bone metastases were considered independently.

\section{Baseline patient characteristics}

Patient characteristics include age, coded as a continuous variable, and then categorized into quartiles: $\leq 63,64-72$, $73-79$ and $\geq 80$ years. Patients under 18 years old were not considered. Gender and race were also examined. Baseline Charlson Comorbidity Index $(\mathrm{CCl})$ was calculated according to Deyo and colleagues ${ }^{16,17}$ and was stratified as follows: 0 , 1,2 and $\geq 3$.

\section{Statistical analyses}

Mean, median and interquartile range were generated for continuously coded variables. Frequencies and proportions were generated for categorical variables.

The analyses consisted of 3 parts. First, the chi-square test was used to assess whether differences between proportions were statistically significant. Then the effect of age on the rate of multiple concomitant metastatic sites was tested in the entire population, and according to the 5 most common metastatic sites and to brain metastases. This was done using the Cochran-Armitage trend statistic. Subsequently, separate multivariable logistic regression models were fitted to test the effect of age on the rates of multiple concomitant metastatic sites. Adjustment was made for gender, race and $\mathrm{CCl}$. Second, we examined the rate of bone metastases in the entire population, as well as according to patient age quartiles, based on the presence of other concomitant metastatic sites. Third and finally, we repeated part two of the analyses focusing on the rate of brain metastases. Analyses were two-sided with a statistical significance set a $p<0.05$ and conducted using the R statistical package (the R foundation for Statistical Computing, version 2.13.1).

\section{Results}

Overall, 7543 patients with mUCUB were identified (Table 1). The median age was 72 years (interquartile range: 63-79). Most patients were male (71\%) and Caucasian (63\%). The rate of single-site metastases was $71 \%$ vs. $29 \%$ for metastases at $\geq 2$ sites. Stratification of patients according to age categories identified 1836, 1839, 1857 and 2011 individuals aged $\leq 63,64-72,73-70$ and $\geq 80$ years, respectively.

The most common sites were lymph nodes $(25.4 \%)$, bone $(24.7 \%)$, urinary $(23.5 \%)$, lung $(19.4 \%)$, liver $(18.1 \%)$ and brain (3.1\%) (Fig. 1). The rate of multiple concomitant metastatic sites decreased with increasing age $(p<0.001)$ (Fig. 2). This phenomenon persisted, even after stratification of patients according to the most common metastatic sites (Fig. 3a, Fig. 3b, Fig. 3c, Fig. 3d, Fig. 3e, Fig. 3f). Specifically, the rates of multiple concomitant metastatic sites decreased with increasing age in patients with lung, bone, liver, urinary tract and brain metastases (all $p \leq 0.04$ ).

Table 2 shows the multivariable logistic regression analyses predicting the rate of multiple concomitant metastatic sites according to patients aged $\leq 63$ and $>63$ years within the entire population and in site-specific metastases. Overall, the youngest patient stratum had a 1.3-fold higher rate of harboring multiple concomitant metastatic sites than older patients $(p<0.001)$. Similarly, patients of the youngest age stratum with brain, lung, liver or bone metastases had 2.2-, $2.0-, 1.8-$ and 1.5 -fold higher rate of harboring multiple concomitant metastatic sites (all $p<0.009$ ). The effect of age failed to reach statistical significance in patients with urinary metastases or lymph node metastases (all $p \geq 0.05$ ).

We also focused on 1860 patients with bone metastases, which represented $25 \%$ of all mUCUB patients. Of those, 1008 patients $(54 \%)$ had exclusive bone metastases, which accounted for $13 \%$ of all mUCUB patients (Fig. 4). The rate of bone metastases was lowest $(15 \%)$ in individuals with abdominal metastases and absence of brain metastases, regardless of the presence or absence of thoracic metastases. Conversely, it was $40 \%$ in patients with concomitant abdominal, thoracic and brain metastases. Similarly, the rate of bone metastases was $36 \%$ in patients with abdominal and brain metastases. The rate of bone metastases in the remainder of the population ranged from $18 \%$ to $30 \%$.

Finally, we focused on 237 (3.1\%) patients with brain metastases. Of those, 93 patients (39\%) had exclusive brain metastases, which represented $1.2 \%$ of all mUCUB patients (Fig. 5). The rate of brain metastases was lowest (1\%) in individuals with abdominal metastases and absence of thoracic or bone metastases. Conversely, it was highest (7\%) in patients with concomitant thoracic and bone metastases. 


\begin{tabular}{|c|c|c|c|c|c|c|}
\hline & Overall & $\leq 63$ years & $64-72$ years & $72-79$ years & $\geq 80$ years & $p$ value $^{\S}$ \\
\hline No. patients & 7543 & $1836(24.3)$ & $1839(24.4)$ & $1857(24.6)$ & $2011(26.7)$ & - \\
\hline \multicolumn{7}{|l|}{ Site of metastases } \\
\hline Lymph node & $1918(25.4)$ & $583(31.8)$ & $527(28.7)$ & $449(24.2)$ & $359(17.9)$ & $<0.001$ \\
\hline Bone & $1860(24.7)$ & $495(27.0)$ & $438(23.8)$ & $444(23.9)$ & $483(24.0)$ & 0.07 \\
\hline Urinary & $1774(23.5)$ & $384(20.9)$ & $446(24.3)$ & $467(25.1)$ & $477(23.7)$ & 0.02 \\
\hline Lung & 1466 (19.4) & $348(19.0)$ & 309 (16.8) & 368 (19.8) & 441 (21.9) & 0.001 \\
\hline Liver & $1368(18.1)$ & $334(18.2)$ & $320(17.4)$ & $343(18.5)$ & $371(18.4)$ & 0.8 \\
\hline Brain & $237(3.1)$ & 89 (4.8) & $64(3.5)$ & $46(2.5)$ & $38(1.9)$ & $<0.001$ \\
\hline \multicolumn{7}{|l|}{ No. metastatic sites } \\
\hline 1 & $5368(71.2)$ & $1221(66.5)$ & 1259 (68.5) & $1341(72.2)$ & 1547 (76.9) & $<0.001$ \\
\hline$\geq 2$ & $2175(28.8)$ & 615 (33.5) & $580(31.5)$ & $516(27.8)$ & $464(23.1)$ & \\
\hline \multicolumn{7}{|l|}{ Sex } \\
\hline Male & 5365 (71.1) & $1348(73.4)$ & $1342(73.0)$ & $1332(71.7)$ & $1343(66.8)$ & $<0.001$ \\
\hline Female & $2178(28.9)$ & $488(26.6)$ & $497(27.0)$ & $525(28.3)$ & $668(33.2)$ & \\
\hline \multicolumn{7}{|l|}{ Race } \\
\hline Caucasian & $4740(62.8)$ & $4740(62.8)$ & $1133(61.6)$ & $1208(65.1)$ & 1371 (68.2) & $<0.001$ \\
\hline African-American & $436(5.8)$ & $436(5.8)$ & $122(6.6)$ & 79 (4.3) & $75(3.7)$ & \\
\hline Hispanic & 278 (3.7) & $278(3.7)$ & $76(4.1)$ & $54(2.9)$ & $62(3.1)$ & \\
\hline Other $^{\dagger}$ & $195(2.6)$ & $195(2.6)$ & $53(2.9)$ & $46(2.5)$ & $45(2.2)$ & \\
\hline Unknown & $1894(25.1)$ & $1894(25.1)$ & $455(24.7)$ & $470(25.3)$ & $458(22.8)$ & \\
\hline \multicolumn{7}{|l|}{$\mathrm{CCl}^{\ddagger}$} \\
\hline 0 & $4538(60.2)$ & $1272(69.3)$ & $1014(55.1)$ & $1059(57.0)$ & 1193 (59.3) & $<0.001$ \\
\hline 1 & $2055(27.2)$ & $371(20.2)$ & $566(30.8)$ & $557(30.0)$ & $561(27.9)$ & \\
\hline 2 & $556(7.4)$ & $111(6.0)$ & $168(9.1)$ & $131(7.1)$ & $146(7.3)$ & \\
\hline$\geq 3$ & $394(5.2)$ & $82(4.5)$ & $91(4.9)$ & $110(5.9)$ & $111(5.5)$ & \\
\hline
\end{tabular}

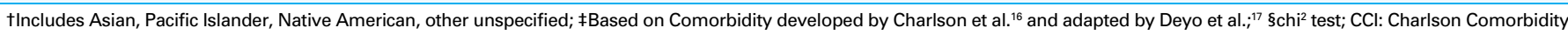
Index.

The rate of brain metastases in the remainder of the population ranged from $2 \%$ to $6 \%$.

\section{Discussion}

The distribution pattern of UCUB metastases is relatively unknown. In previous studies, the rate of bone metastases ranged from $32 \%$ to $47 \%$ among mUCUB patients. ${ }^{18-20}$ In comparison, the rate of brain metastases ranged from $3 \%$ to $5 \%{ }^{18-20}$ Unfortunately, these data originate primarily from single institutional data with small sample sizes $(n=150$ 251). Moreover, it is not known how age affects metastases in UCUB patients. Based on the paucity of data with regard to these considerations, we examined the association between age and distribution of metastatic sites in mUCUB patients. In addition, we performed a subset analysis focusing on patients with brain ${ }^{11}$ and bone ${ }^{12,13}$ metastases, since these patients represent particularly high-risk individuals.

Several of our findings are noteworthy. We found that the overall rate of metastases at single versus multiple concomitant metastatic sites demonstrated an age-related distribution. Specifically, younger individuals had higher rates of multiple concomitant metastatic sites. This phenomenon was subsequently confirmed in several analyses of specific metastatic sites, namely lung, bone, liver, urinary tract and brain. In multivariable analyses, young age represented an independent predictor of the presence of multiple concomitant metastatic sites in the entire population. The increase in the rates of multiple concomitant metastases ranged from 1.5 - to 2.2 -fold higher in patients $\leq 63$ versus $>63$ years (all $p \leq 0.009$ ), which indicates that young age might be inversely related to the number of site-specific metastases. We corroborate the findings of a previous institutional series, where patients younger than 60 years more often had metastases to the bones, lymph nodes, lung and liver. ${ }^{19}$ From a practical perspective, this implies that younger hospitalized patients with mUCUB are more likely to harbor more than 1 site of metastatic disease regardless of the applied tabulation scheme; they therefore should be imaged more extensively. The underlying reason could be that younger patients undergo more extensive staging, have more metastases because they receive more aggressive treatment than older patients and thus have a longer time to develop additional metastases. Moreover, tumours in younger patients might be associated with more aggressive genomic alterations.

Furthermore, we examined the rates of bone metastases according to the presence or absence of multiple concomitant metastatic sites. The overall rate of bone metastases was $25 \%$ in the entire study population, whereas $13 \%$ had exclusive bone metastases. A detailed stratification scheme 


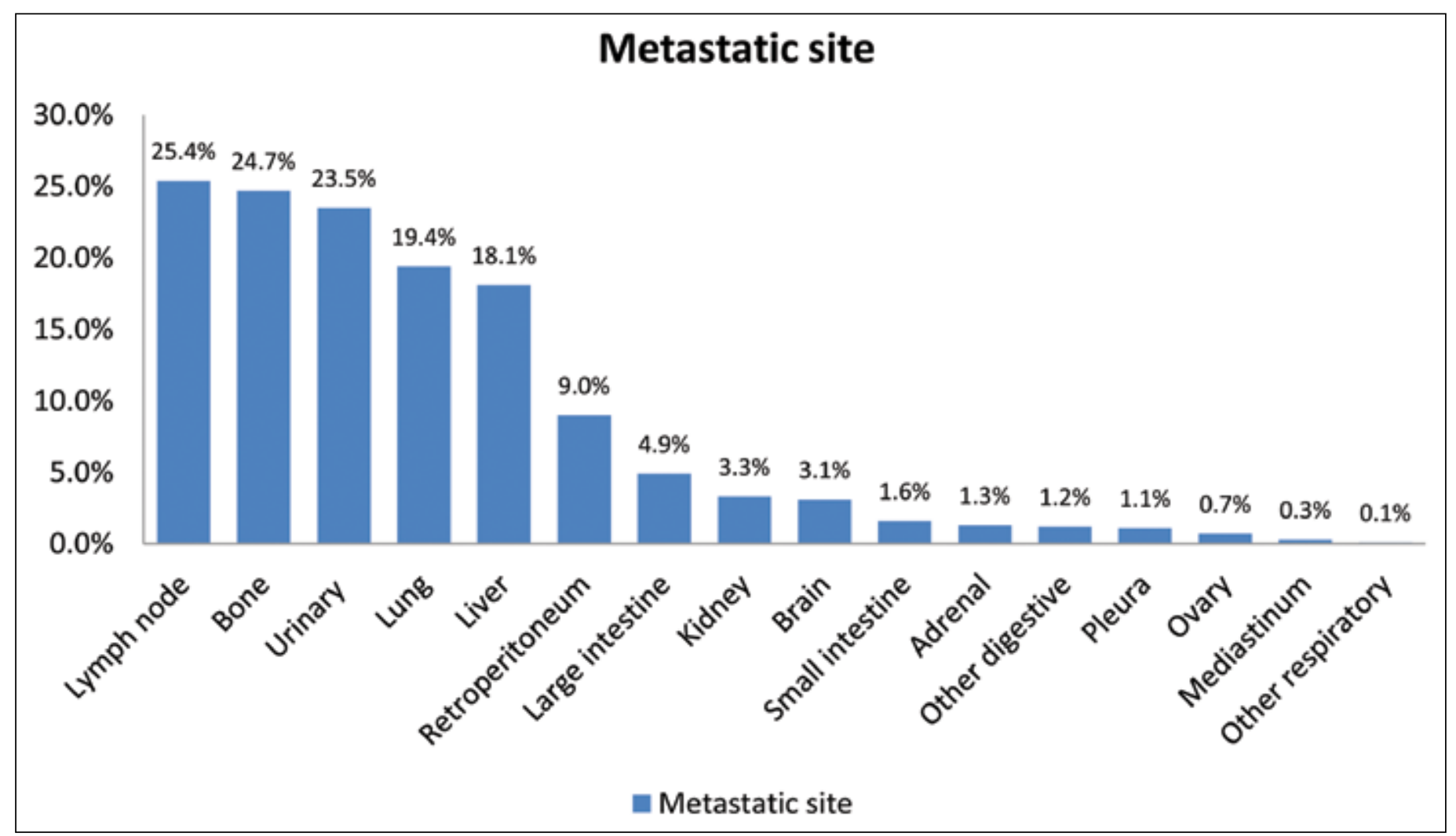

Fig. 1. The distribution of metastatic sites in patients with bladder cancer $(n=7543)$, Nationwide Inpatient Sample, 1998-2007 (the rates add up to more than $100 \%$ because some patients have multiple metastatic sites).

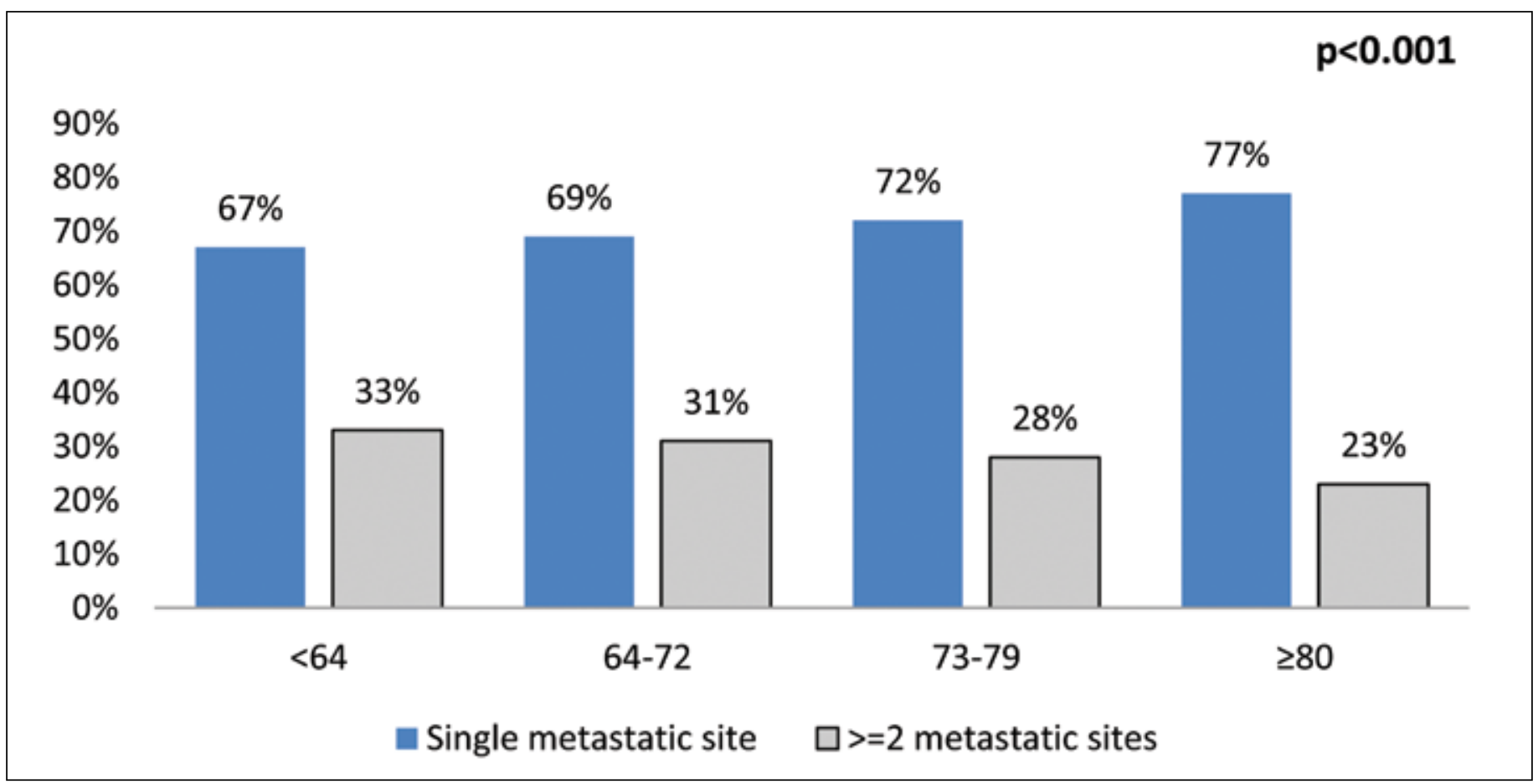

Fig. 2. The distribution of metastases in a single versus multiple concomitant sites, stratified according to age categories $(n=7543)(p<0.001)$. 


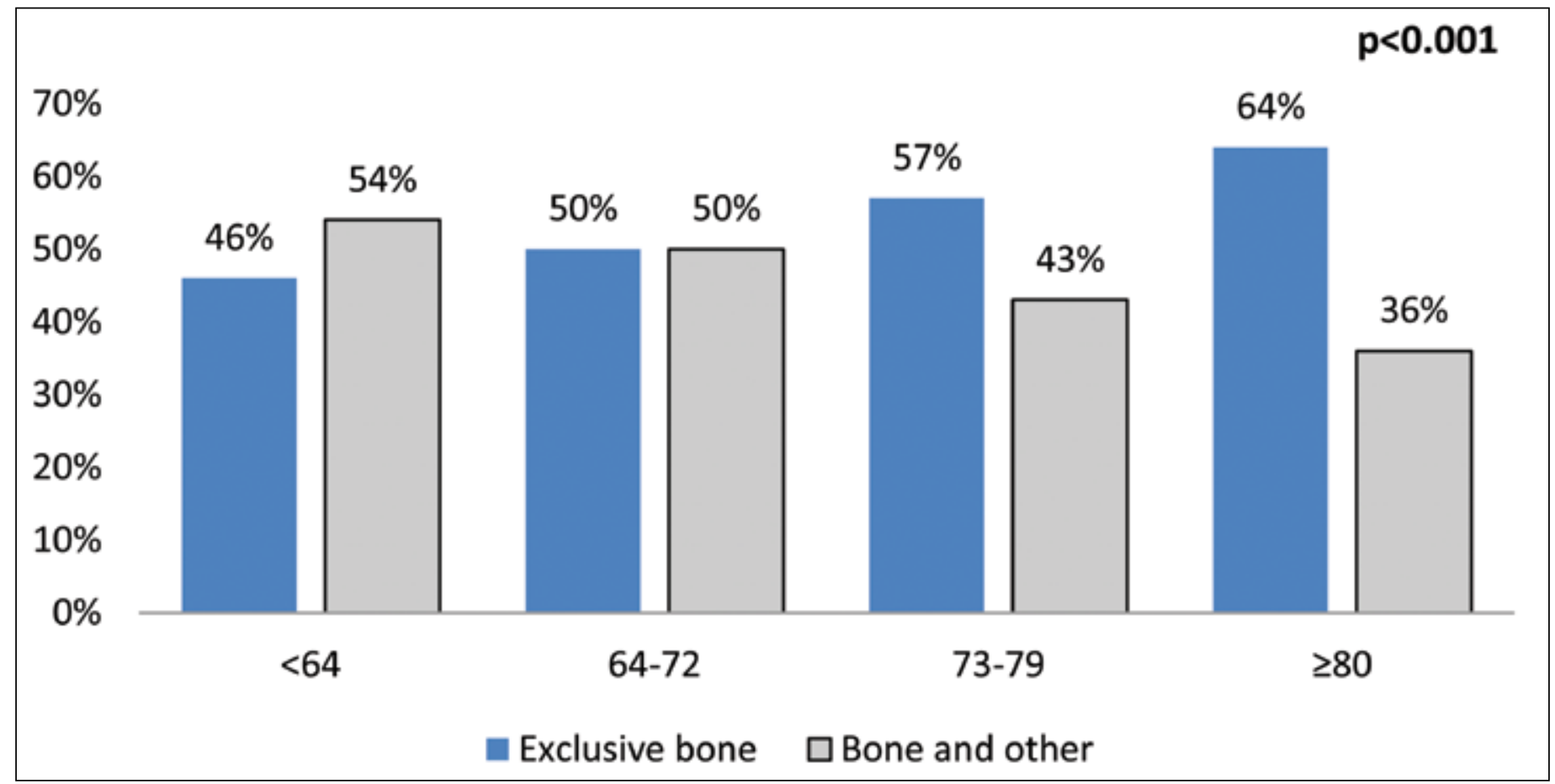

Fig. 3a. The distribution of metastases in a single versus multiple concomitant sites, stratified according to age categories, in the bone.

focusing on the rate of bone metastases demonstrated 2 key observations. First, the rate of bone metastases was highest in patients with concomitant abdominal, thoracic and brain metastases (40\%). Second, conversely, the low- est rate of bone metastases was identified in patients with abdominal metastases, as well as in patients with abdominal and thoracic metastases but without brain metastases $(15 \%)$. Taken together, our data demonstrate a substantial

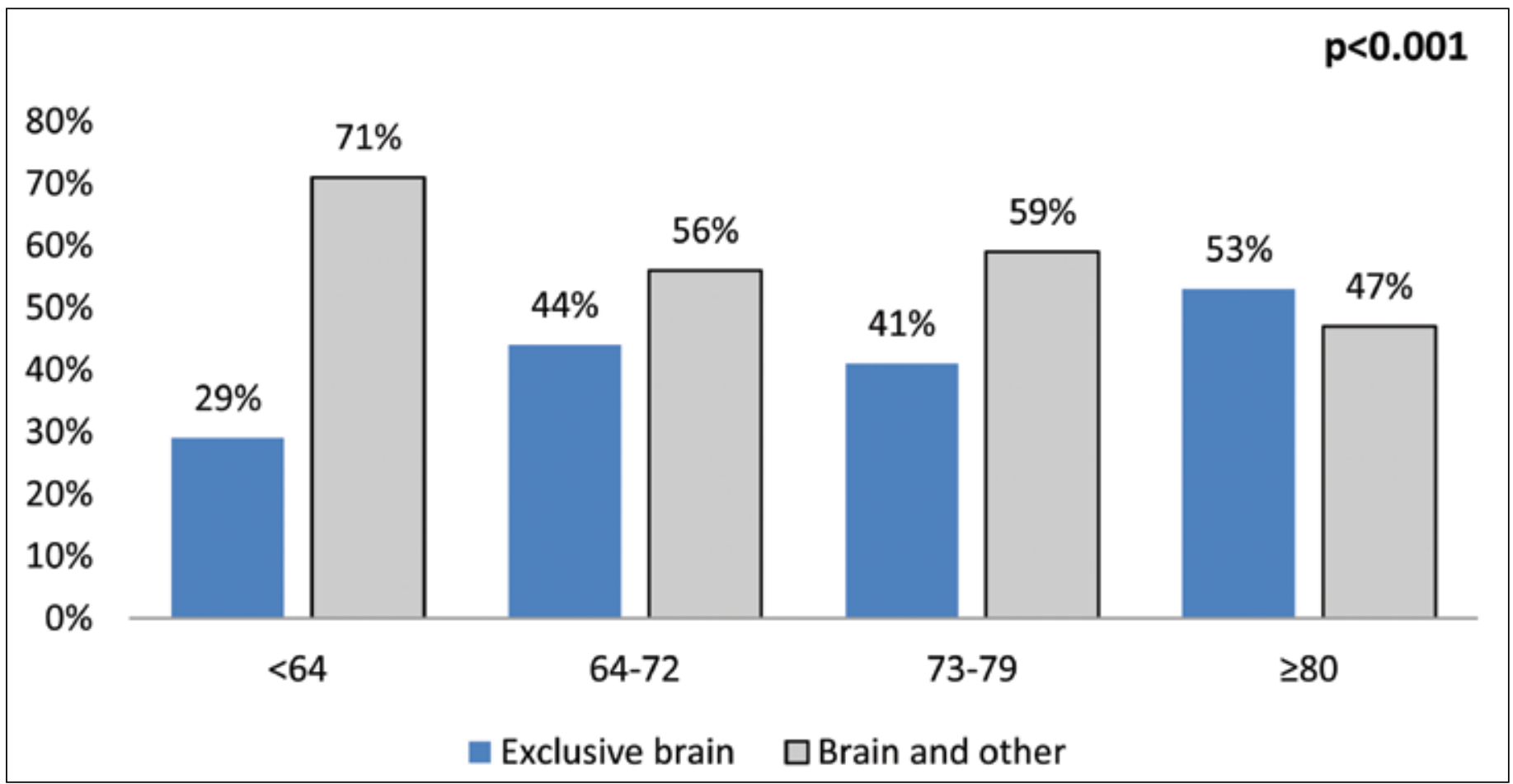

Fig. 3b. The distribution of metastases in a single versus multiple concomitant sites, stratified according to age categories, in the brain. 


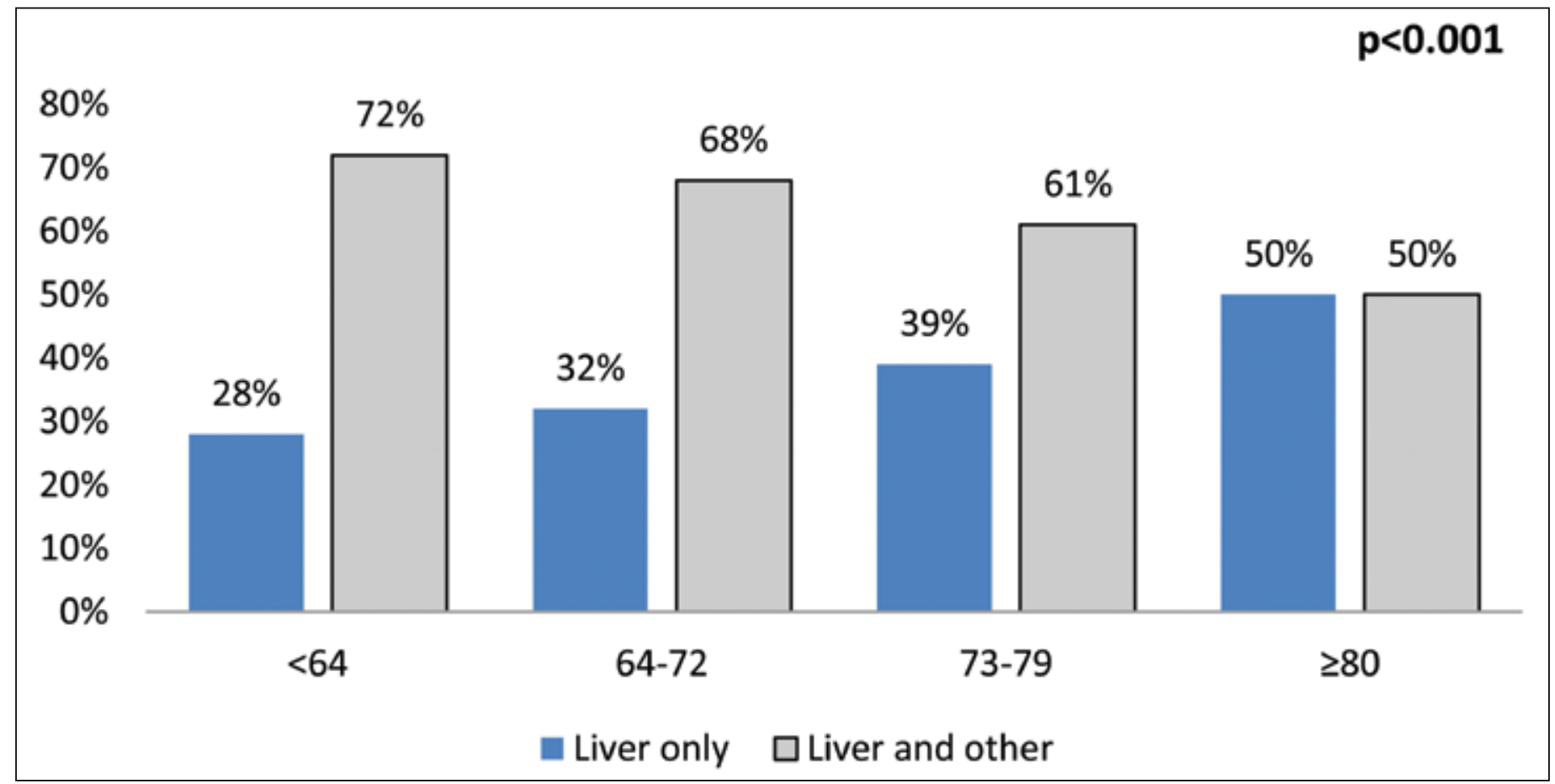

Fig. 3c. The distribution of metastases in a single versus multiple concomitant sites, stratified according to age categories, in the liver.

heterogeneity with regard to the rate of bone metastases in this large population-based cohort (15\% to $40 \%)$. Even in the best-case scenario (abdominal metastases, no thoracic or brain metatases), about 1 out of 6 hospitalized individuals with mUCUB will harbor bone metastases. From a clinical perspective, this implies that bone scans or skeletal surveys could be performed more regularly in these patients. Currently, about $10 \%$ of patients will present with metastatic

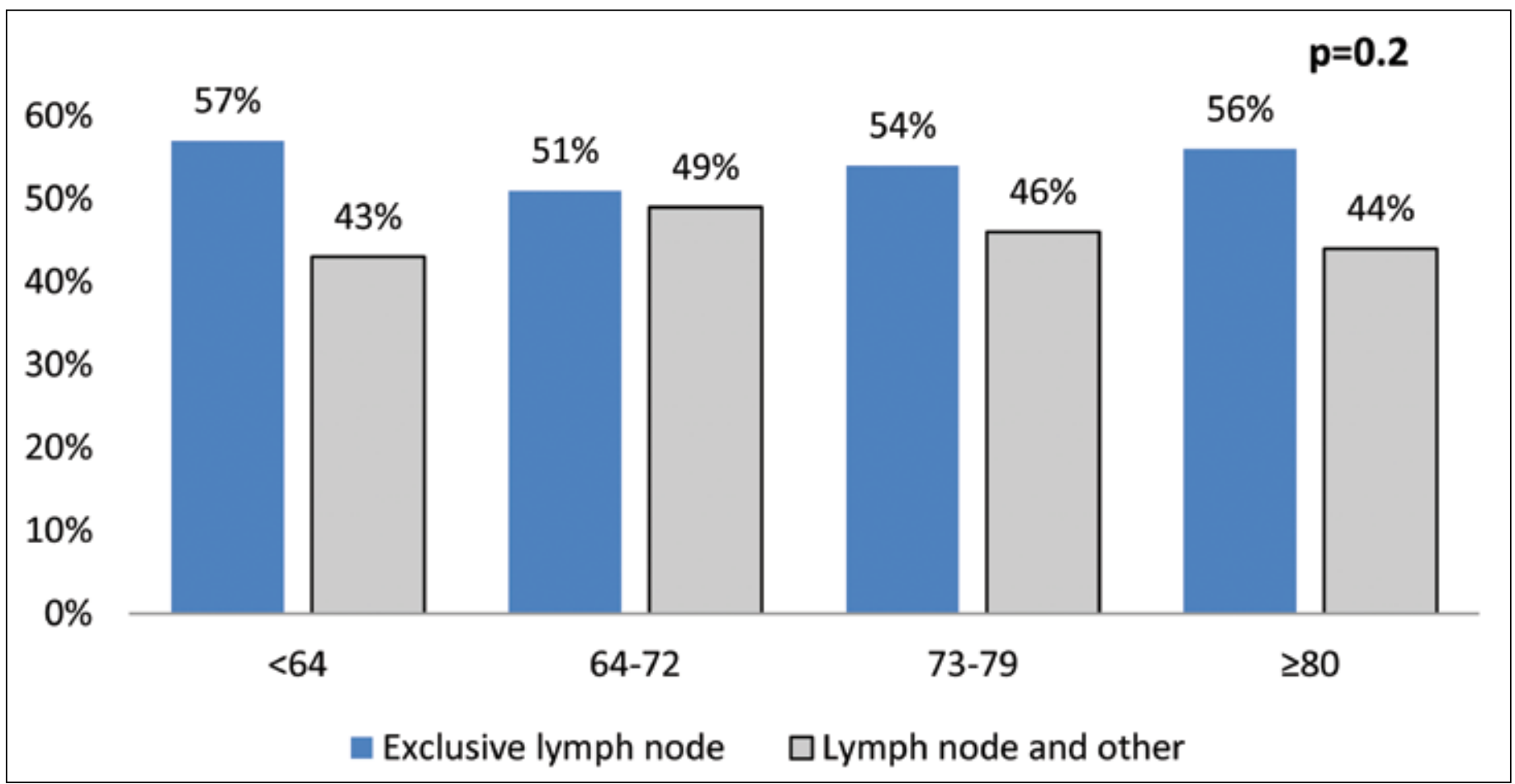

Fig. 3d. The distribution of metastases in a single versus multiple concomitant sites, stratified according to age categories, in the lymph nodes. 


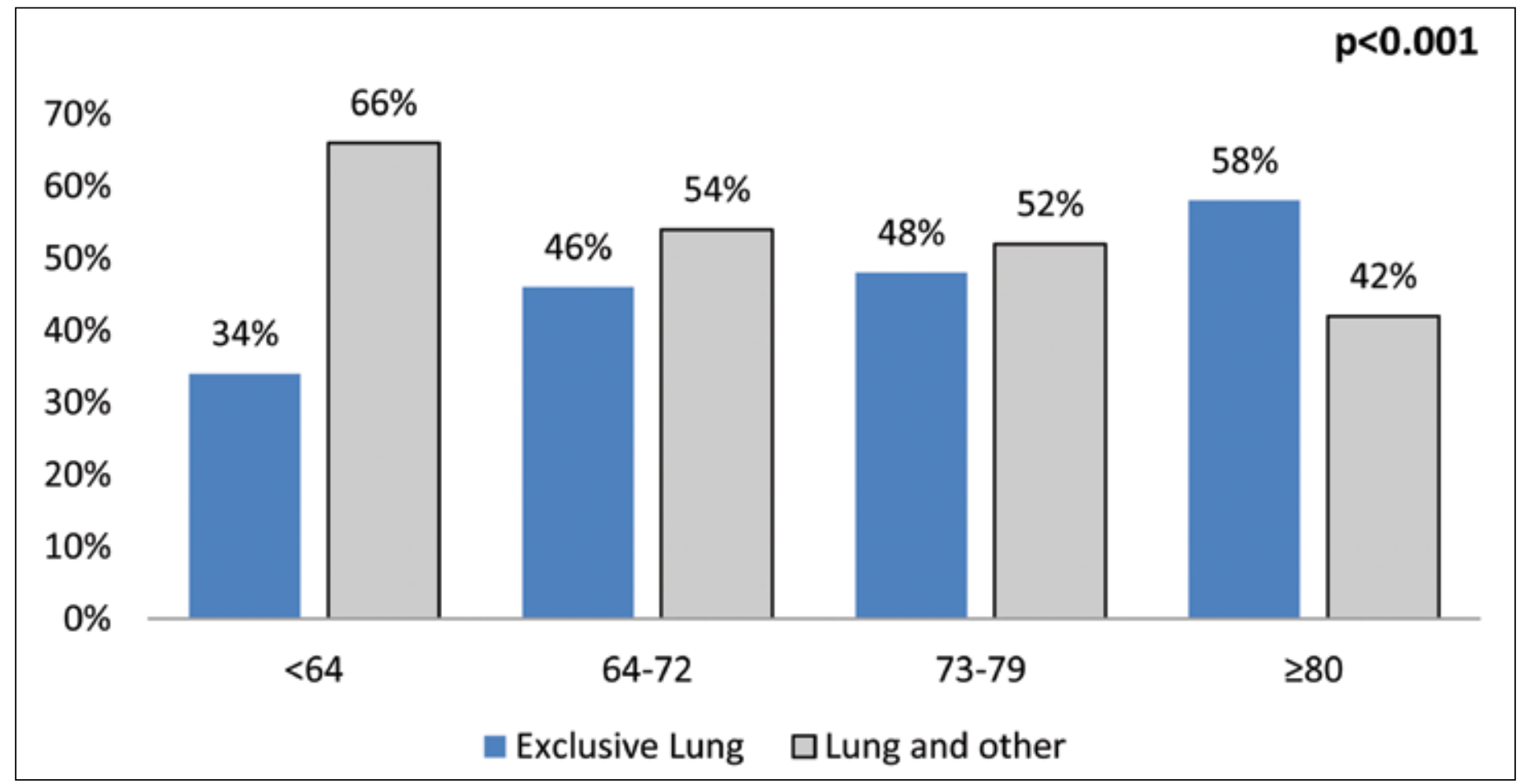

Fig. 3e. The distribution of metastases in a single versus multiple concomitant sites, stratified according to age categories, in the lungs.

UCUB at diagnosis. ${ }^{21}$ Based on our data, at least 1 in 4 hospitalized patients with mUCUB will harbor bone metastases. In high-risk patients, such as those with thoracic and brain metastases, virtually every second individual harbors bone metastases. The availability of effective measures to prevent skeletal-related events, such as bisphosphonates ${ }^{22}$

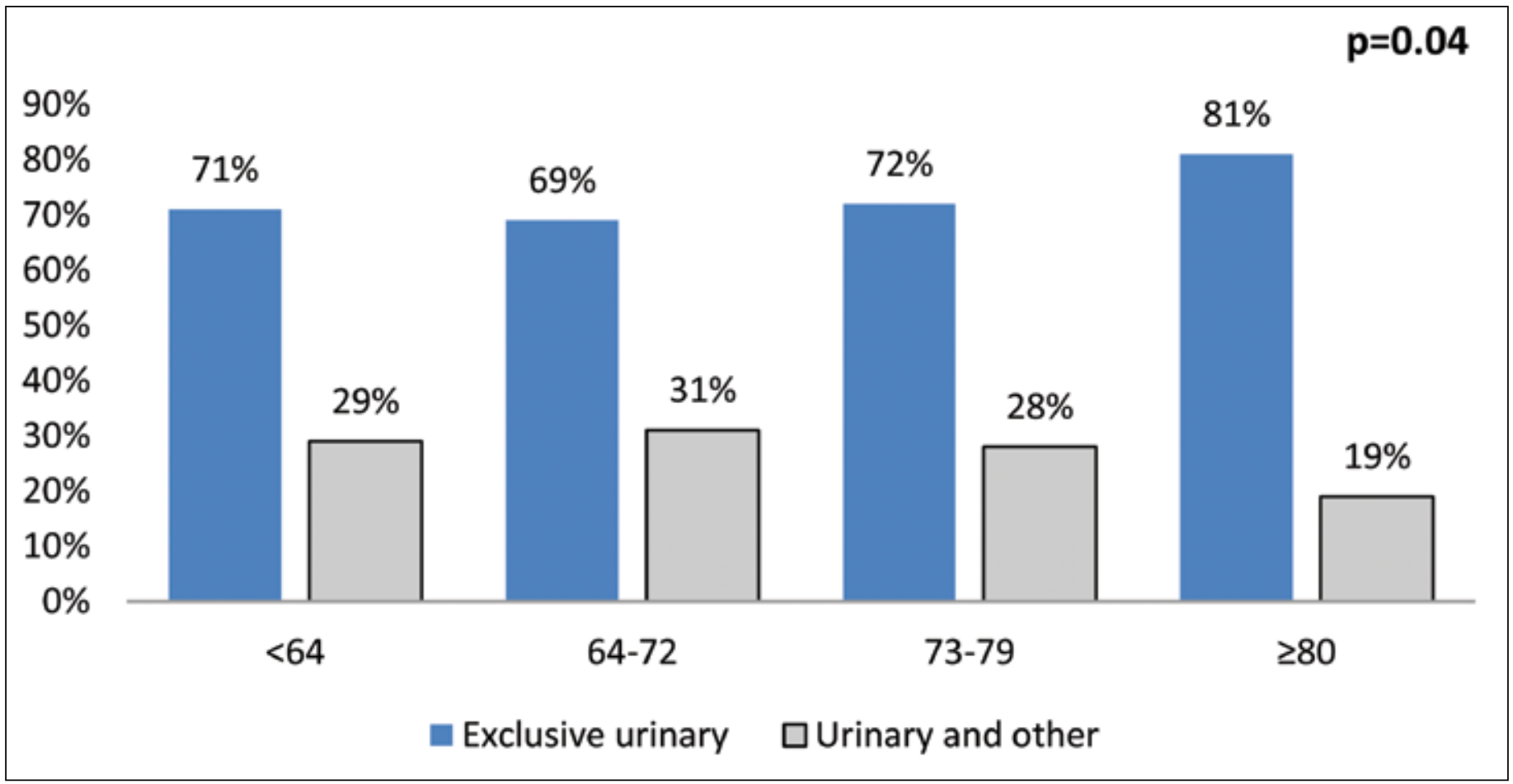

Fig. 3f. The distribution of metastases in a single versus multiple concomitant sites, stratified according to age categories, in the urinary tract. 


\begin{tabular}{|c|c|c|c|c|c|c|c|c|c|c|c|c|c|c|}
\hline $\begin{array}{l}\text { Metastatic } \\
\text { site }\end{array}$ & Overall & & Brain & & Lung & & Liver & & Bone & & Urinary & & $\begin{array}{l}\text { Lymph } \\
\text { node }\end{array}$ & \\
\hline & $\begin{array}{l}\text { OR } \\
\text { (95\%- } \\
\text { Cl) }\end{array}$ & $\begin{array}{c}p \\
\text { value }\end{array}$ & $\begin{array}{l}\text { OR } \\
(95 \%- \\
\text { Cl) }\end{array}$ & $\begin{array}{c}p \\
\text { value }\end{array}$ & $\begin{array}{l}\text { OR } \\
(95 \%- \\
\text { Cl) }\end{array}$ & $p$ value & $\begin{array}{l}\text { OR } \\
\text { (95\%- } \\
\text { Cl) }\end{array}$ & $\begin{array}{c}p \\
\text { value }\end{array}$ & $\begin{array}{l}\text { OR } \\
(95 \%- \\
\text { Cl) }\end{array}$ & $\begin{array}{c}p \\
\text { value }\end{array}$ & $\begin{array}{c}\text { OR } \\
\text { (95\%-CI) }\end{array}$ & $\begin{array}{c}p \\
\text { value }\end{array}$ & $\begin{array}{c}\text { OR } \\
(95 \%-\mathrm{Cl})\end{array}$ & $p$ value \\
\hline $\begin{array}{l}\text { Age (ref. }>63 \\
\text { years) } \\
\leq 63\end{array}$ & $\begin{array}{l}1.35 \\
(1.2- \\
1.51)\end{array}$ & $<0.001$ & $\begin{array}{c}2.19 \\
(1.22- \\
3.95)\end{array}$ & 0.009 & $\begin{array}{c}2.02 \\
(1.57- \\
2.61)\end{array}$ & $<0.001$ & $\begin{array}{c}1.81 \\
(1.38- \\
2.38)\end{array}$ & $<0.001$ & $\begin{array}{c}1.52 \\
(1.24- \\
1.88)\end{array}$ & $<0.001$ & $\begin{array}{c}1.21 \\
(0.94- \\
1.56)\end{array}$ & 0.144 & $\begin{array}{c}0.85 \\
(0.70- \\
1.04)\end{array}$ & 0.117 \\
\hline \multicolumn{15}{|l|}{$\begin{array}{l}\text { Race (ref.: } \\
\text { Caucasian) }\end{array}$} \\
\hline $\begin{array}{l}\text { African- } \\
\text { American }\end{array}$ & $\begin{array}{c}0.97 \\
(0.78- \\
1.20)\end{array}$ & 0.752 & $\begin{array}{c}0.24 \\
(0.07- \\
0.77)\end{array}$ & 0.016 & $\begin{array}{c}0.87 \\
(0.58- \\
1.30)\end{array}$ & 0.487 & $\begin{array}{c}1.02 \\
(0.64- \\
1.63)\end{array}$ & 0.925 & $\begin{array}{c}0.99 \\
(0.67- \\
1.47)\end{array}$ & 0.974 & $\begin{array}{r}1.35 \\
(0.83- \\
2.19)\end{array}$ & 0.227 & $\begin{array}{r}0.96 \\
(0.62- \\
1.49)\end{array}$ & 0.863 \\
\hline Hispanic & & 0.060 & & 0.587 & & 0.200 & & 0.592 & & 0.996 & & 0.464 & & 0.681 \\
\hline Other ${ }^{\dagger}$ & $\begin{array}{c}1.28 \\
(0.99- \\
1.65)\end{array}$ & 0.977 & $\begin{array}{c}1.60 \\
(0.29- \\
8.83)\end{array}$ & 0.373 & $\begin{array}{c}1.40 \\
(0.84- \\
2.34)\end{array}$ & 0.483 & $\begin{array}{c}0.87 \\
(0.53- \\
1.44)\end{array}$ & 0.586 & $\begin{array}{c}1.00 \\
(0.58- \\
1.72)\end{array}$ & 0.422 & $\begin{array}{c}1.28 \\
(0.66- \\
2.45)\end{array}$ & 0.057 & $\begin{array}{c}1.10 \\
(0.70- \\
1.74)\end{array}$ & 0.444 \\
\hline & 1.01 & & 2.83 & & 0.77 & & 0.83 & & 0.79 & & 1.73 & & 1.23 & \\
\hline \multirow[t]{2}{*}{ Unknown } & $\begin{array}{l}(0.73- \\
1.38)\end{array}$ & 0.710 & $\begin{array}{l}(0.29- \\
27.94)\end{array}$ & 0.365 & $\begin{array}{l}(0.37- \\
1.59)\end{array}$ & 0.747 & $\begin{array}{l}(0.41- \\
1.65)\end{array}$ & 0.983 & $\begin{array}{l}(0.44- \\
1.41)\end{array}$ & 0.155 & $\begin{array}{l}(0.98- \\
3.04)\end{array}$ & 0.518 & $\begin{array}{l}(0.72- \\
2.09)\end{array}$ & 0.973 \\
\hline & $\begin{array}{c}1.02 \\
(0.91- \\
1.15)\end{array}$ & & $\begin{array}{l}0.75 \\
(0.4- \\
1.40)\end{array}$ & & $\begin{array}{c}0.96 \\
(0.75- \\
1.24)\end{array}$ & & $\begin{array}{c}1.00 \\
(0.77- \\
1.30)\end{array}$ & & $\begin{array}{c}1.17 \\
(0.94- \\
1.45)\end{array}$ & & $\begin{array}{c}0.92 \\
(0.71- \\
1.19)\end{array}$ & & $\begin{array}{c}1.00 \\
(0.81- \\
1.24)\end{array}$ & \\
\hline $\begin{array}{l}\text { Gender (ref.: } \\
\text { Male) }\end{array}$ & $\begin{array}{c}1.10 \\
(0.98- \\
1.22)\end{array}$ & 0.104 & $\begin{array}{c}1.45 \\
(0.74- \\
2.84)\end{array}$ & 0.275 & $\begin{array}{c}0.99 \\
(0.79- \\
1.25)\end{array}$ & 0.953 & $\begin{array}{c}1.00 \\
(0.78- \\
1.29)\end{array}$ & 0.984 & $\begin{array}{c}0.99 \\
(0.80- \\
1.22)\end{array}$ & 0.921 & $\begin{array}{r}1.43 \\
(1.13- \\
1.80)\end{array}$ & 0.003 & $\begin{array}{c}1.04 \\
(0.85- \\
1.27)\end{array}$ & 0.682 \\
\hline \multicolumn{15}{|l|}{$\mathrm{CCl}$ (ref.: 0) } \\
\hline 1 & $\begin{array}{c}1.04 \\
(0.93-\end{array}$ & 0.494 & $\begin{array}{r}1.05 \\
(0.56-\end{array}$ & 0.882 & $\begin{array}{c}0.87 \\
(0.69-\end{array}$ & 0.245 & $\begin{array}{c}1.05 \\
(0.81-\end{array}$ & 0.734 & $\begin{array}{r}1.02 \\
(0.82-\end{array}$ & 0.881 & $\begin{array}{c}1.04 \\
(0.81-\end{array}$ & 0.782 & $\begin{array}{r}1.03 \\
(0.84-\end{array}$ & 0.760 \\
\hline 2 & $\begin{array}{l}1.17) \\
0.87\end{array}$ & 0.178 & $\begin{array}{l}1.96) \\
0.64\end{array}$ & 0.446 & $\begin{array}{l}1.10) \\
0.78\end{array}$ & 0.229 & $\begin{array}{l}1.36) \\
0.87\end{array}$ & 0.513 & $\begin{array}{l}1.26) \\
1.00\end{array}$ & 1.000 & $\begin{array}{l}1.33) \\
0.82\end{array}$ & 0.420 & $\begin{array}{l}1.28) \\
0.67\end{array}$ & 0.029 \\
\hline$\geq 3$ & $\begin{array}{c}(0.71- \\
1.07) \\
1.27 \\
(1.02- \\
1.59)\end{array}$ & 0.031 & $\begin{array}{c}(0.21- \\
2.00) \\
0.64 \\
(0.14- \\
3.01)\end{array}$ & 0.576 & $\begin{array}{c}(0.52- \\
1.17) \\
1.14 \\
(0.70- \\
1.87)\end{array}$ & 0.593 & $\begin{array}{c}(0.57- \\
1.32) \\
1.00 \\
(0.64- \\
1.56)\end{array}$ & 0.994 & $\begin{array}{c}(0.71- \\
1.42) \\
1.04 \\
(0.66- \\
1.64)\end{array}$ & 0.857 & $\begin{array}{c}(0.51- \\
1.33) \\
1.71 \\
(1.09- \\
2.68)\end{array}$ & 0.020 & $\begin{array}{c}(0.47- \\
0.96) \\
1.15 \\
(0.75- \\
1.76)\end{array}$ & 0.518 \\
\hline
\end{tabular}

Cl: confidence interval; OR: odds ratio; CCl: Charlson Comorbidity Index.

or radiotherapy, represents an additional reason for detailed bone imaging.

We also examined the rates of brain metastases according to the presence or absence of multiple concomitant metastatic sites. The overall rate of brain metastases was 3\% in the entire population of hospitalized patients, whereas exclusive brain metastases were recorded in $0.9 \%$. Following stratification, the rate of brain metastases ranged from $1 \%$ in individuals with exclusive abdominal metastases, to $6 \%$ to $7 \%$ in patients with concomitant thoracic and bone metastases and abdominal, thoracic and bone metastases. The remainder of the population harbored an intermediate rate of brain metastases $(2 \%-4 \%)$. Consequently, patients with thoracic and/or bone metastases might benefit from brain imaging.

The current European Association of Urology (EAU) EAU guidelines recommend brain and bone imaging in symptomatic individuals with central nervous system (CNS) symptoms ${ }^{21}$ whereas the National Comprehensive Cancer Network (NCCN) recommends bone imaging in symptomatic patients, while there is no specific recommendation for brain imaging. ${ }^{23}$ Nevertheless, the present study might provide additional information on the probability of brain and bone metastases among hospitalized patients with mUCUB and might help to identify high-risk groups that could benefit from early detection even if symptoms are not yet present.

Our study has several limitations inherent to an observational, retrospective study using a claims-based dataset. First, the nature of the database, which focuses primarily on hospitalized patients only, resulted in the omission of mUCUB individuals who never required a hospital stay. It is possible that such individuals have a lower burden of disease, smaller number of metastatic sites and a more favourable prognosis. Second, the NIS relies on ICD-9 codes for assessment of secondary diagnostic codes, which may be subject 


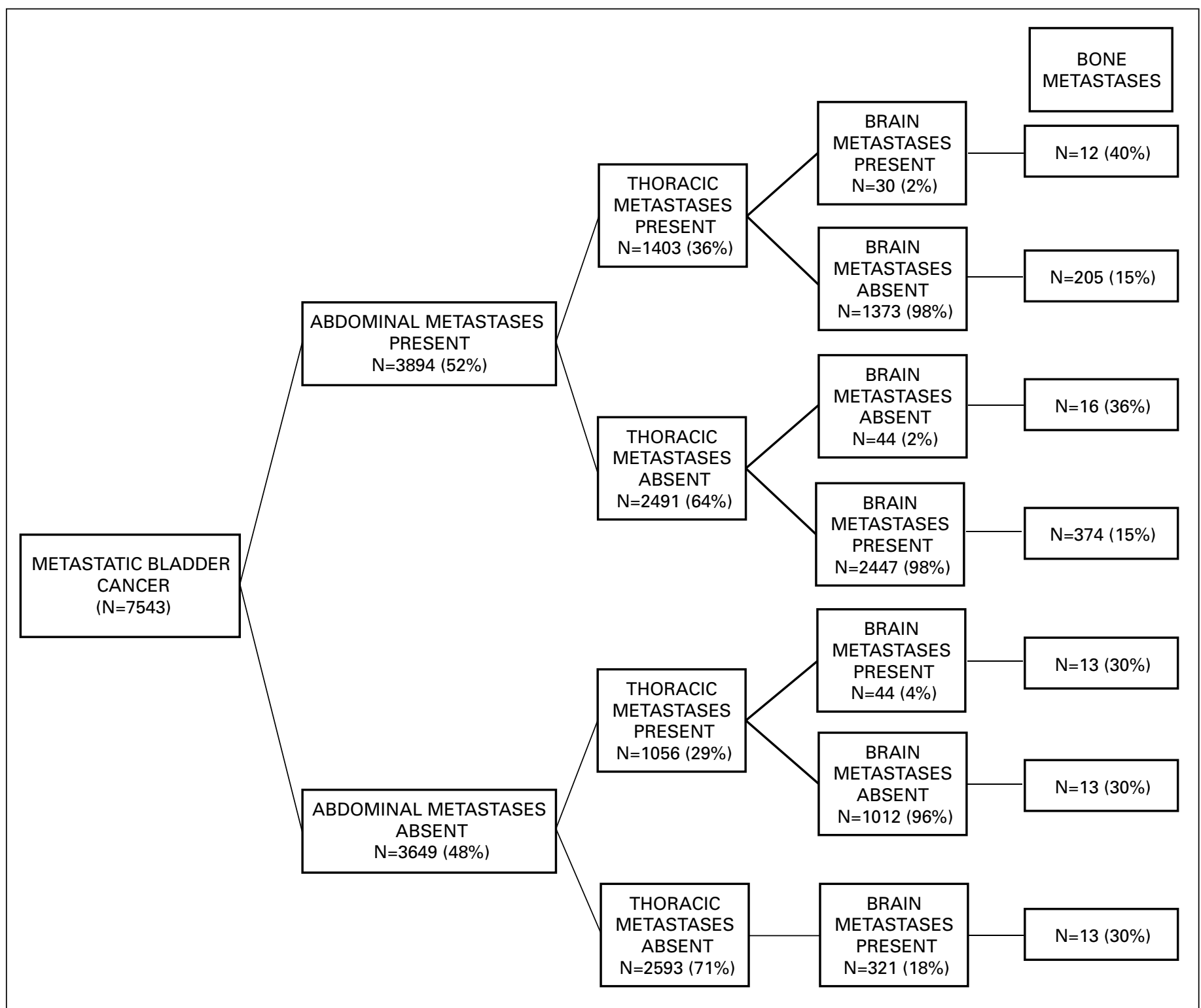

Fig. 4. The rates of bone metastases according to the presence of other established synchronous metastatic sites.

to potential coding biases. Nonetheless, NIS estimates are considered to be precise and accurate, even though they have not been especially tested for the accuracy in reporting metastases. ${ }^{14,15}$ Third, the NIS does not contain information on performance status, symptom score or multiple visits. Fourth, missing information regarding pathological subcategories of UCUB, length of disease, prior radiotherapy or cystectomy, and the use of systemic therapy could bias our results.

\section{Conclusion}

We report a higher number of concomitant metastatic sites in young hospitalized UCUB patients. Bone metastases are frequent in all patients groups, whereas brain metastases are common in UCUB patients with thoracic and/or bone metastases.

Competing interests: Dr. Bianchi, Dr. Roghmann, Dr. Becker, Dr. Sukumar, Dr. Briganti, Dr. Menon, Dr. Karakiewicz, Dr. Sun and Dr. Noldus all declare no competing financial or personal interests. Dr. Trinh has received consultant fees from Intuitive Surgical.

This paper has been peer-reviewed. 


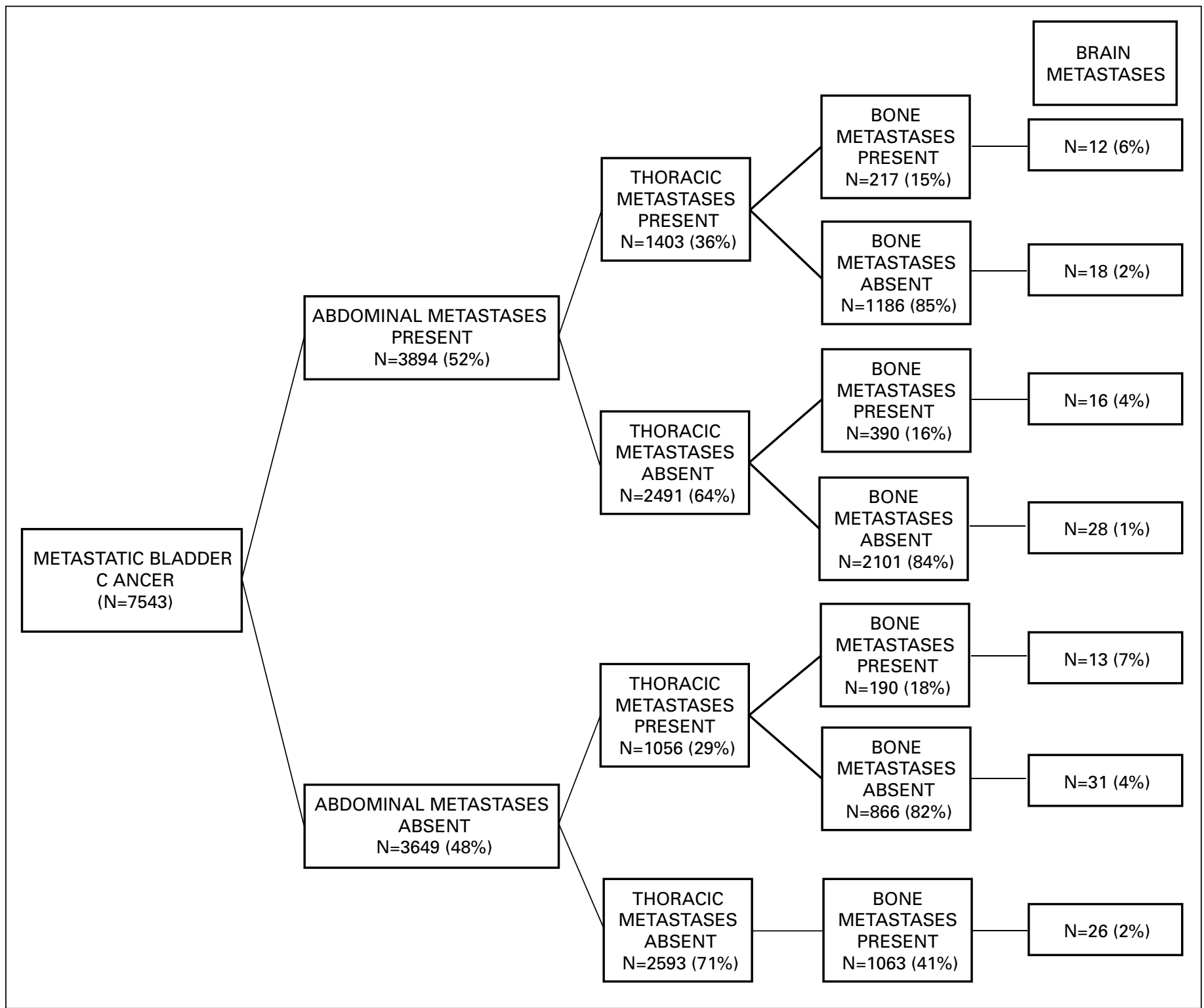

Fig. 5. The rates of brain metastases according to the presence of other established synchronous metastatic sites.

\section{References}

1. Siegel R, Ward E, Brawley 0, et al. Cancer statistics, 2011: The impact of eliminating socioeconomic and racial disparities on premature cancer deaths. CA Cancer I Clin 2011;61:212-36. http://dx.doi. org/10.3322/caac.20121

2. Sonpavde G, Sternberg CN, Rosenberg JE, et al. Second-line systemic therapy and emerging drugs for metastatic transitional-cell carcinoma of the urothelium. Lancet Oncol 2010;11:861-70. http://dx.doi. org/10.1016/S1470-2045(10)70086-3

3. Siegel R, Naishadham D, Jemal A. Cancer statistics, 2013. CA Cancer J Clin 2013;63:11-30. http:// dx.doi.org/10.3322/caac.21166

4. Bharat A, Aft RL, Gao F, et al. Patient and tumor characteristics associated with increased mortality in young women ( $\leq 40$ years) with breast cancer. J Surg Oncol 2009;100:248-51. http://dx.doi. org/10.1002/iso.21268

5. Derwinger K, Kodeda K, Geriy R. Age aspects of demography, pathology and survival assessment in colorectal cancer. Anticancer Res 2010;30:5227-31.
6. Nakamura R, Saikawa Y, Takahashi T, et al. Retrospective analysis of prognostic outcome of gastric cancer in young patients. Int I Clin Oncol 2011;16:328-34. http://dx.doi.org/10.1007/s10147011-0185-7. Epub 2011 Feb 8.

7. Sanchez-Ortiz RF, Rosser CJ, Madsen LT, et al. Young age is an independent prognostic factor for survival of sporadic renal cell carcinoma. J Urol 2004;171:2160-5. http://dx.doi.org/10.1097/01. ju.0000125487.96469.2e

8. Bianchi $M$, Sun $M$, Jeldres $C$, et al. Distribution of metastatic sites in renal cell carcinoma: A population-based analyses. Ann Oncol 2012;23:973-80. http://dx.doi.org/10.1093/annonc/mdr362. Epub 2011 Sep 2.

9. Argani P, Olgac S, Tickoo SK, et al. Xp 11 Translocation renal cell carcinoma in adults: Expanded clinical, pathologic, and genetic spectrum. Am I Surg Pathol 2007;31:1149-60. http://dx.doi.org/10.1097/ PAS.0b013e318031ffff

10. Meyer PN, Clark Jl, Flanigan RC, et al. Xp 11.2 Translocation renal cell carcinoma with very aggressive course in five adults. Am J Clin Pathol 2007;128:70-9. http://dx.doi.org/10.1309/LR5GIVMXPY3GOCUK

11. Mahmoud-Ahmed AS, Suh JH, Kupelian PA, et al. Brain metastases from bladder carcinoma: presentation, treatment and survival. J Urol 2002;167:2419-22. http://dx.doi.org/10.1016/S00225347(05)64996-8 
Bianchi et al.

12. Saxman SB, Propert KJ, Einhorn LH, et al. Long-term follow-up of a phase III intergroup study of cisplatin alone or in combination with methotrexate, vinblastine, and doxorubicin in patients with metastatic urothelial carcinoma: A cooperative group study. J Clin Oncol 1997; 15:2564-9.

13. Bajorin DF, Dodd PM, Mazumdar M, et al. Long-term survival in metastatic transitional-cell carcinoma and prognostic factors predicting outcome of therapy. J Clin Oncol 1999;17:3173-81.

14. Healthcare Cost and Utilization Project (H-CUP): Quality Control Procedures; 2008:29.

15. Whalen D, Houchens R, Elixhauser A. Final 2000 NIS Comparison Report. 2003. HCUP Methods Series Report \#2003-1. U.S. Agency for Healthcare Research and Quality. http://www.hcup-us.ahrq.gov/db/ nation/nis/reports/NIS_Comparison_Report_2000.pdf. Accessed February 25, 2014.

16. Charlson ME, Pompei P, Âles KL, et al. A new method of classifying prognostic comorbidity in longitudinal studies: development and validation. J Chronic Dis 1987;40:373-83. http://dx.doi.org/10.1016/00219681(87)90171-8

17. Deyo RA, Cherkin DC, Ciol MA. Adapting a clinical comorbidity index for use with ICD-9-CM administrative databases. J Clin Epidemiol 1992;45:613-9. http://dx.doi.org/10.1016/0895-4356(92)90133-8

18. Shinagare $A B$, Ramaiya NH, Jagannathan JP, et al. Metastatic pattern of bladder cancer: Correlation with the characteristics of the primary tumor. AJR Am J Roentgenol 2011;196:117-22. http://dx.doi. org/10.2214/AJR.10.5036

19. Sengelov L, Kamby C, von der Maase H. Pattern of metastases in relation to characteristics of primary tumor and treatment in patients with disseminated urothelial carcinoma. J Urol 1996; 155:11 1-4. http:// dx.doi.org/10.1016/50022-5347(01)66562-5

20. Wallmeroth A, Wagner U, Moch H, et al. Patterns of metastasis in muscle-invasive bladder cancer (pT2-4): An autopsy study on 367 patients. Urol Int 1999;62:69-75. http://dx.doi.org/10.1159/000030361

21. Clark PE, Agarwal N, Biagioli MC, et al. Bladder cancer. J Natl Compr Canc Netw 2013;11:446-75.

22. Gakis G, Efstathiou J, Lerner SP, et al. ICUD-EAU International Consultation on Bladder Cancer 2012: Radical cystectomy and bladder preservation for muscle-invasive urothelial carcinoma of the bladder. Eur Urol 2013;63:45-57. http://dx.doi.org/10.1016/i.eururo.2012.08.009

23. Zaghloul MS, Boutrus R, El-Hossieny $\mathrm{H}$, et al. A prospective, randomized, placebo-controlled trial of zoledronic acid in bony metastatic bladder cancer. Int J Clin Oncol 2010;15:382-9. http://dx.doi. org/10.1007/s10147-010-0074-5

Correspondence: Dr. Florian Roghmann, Cancer Prognostics and Health Outcomes Unit, University of Montreal Health Centre, Montreal, QC; f.roghmann@gmail.com

\begin{tabular}{lc}
\hline $\begin{array}{l}\text { Appendix 1. International Classification of Diseases, 9th } \\
\text { edition Clinical Modification (ICD-9-CM) code }\end{array}$ \\
\hline Characteristic & ICD-9-CM code \\
\hline Bladder cancer & 188.0 \\
Metastatic site & \\
Lung & 197.0 \\
Pleura & 197.2 \\
Other respiratory organs & 197.3 \\
Bone/bone marrow & 198.5 \\
& $196.2,196.3,196.5$, \\
Lymph node & $196.6,196.8,196.9$ \\
Liver & 197.7 \\
Adrenal gland & 198.7 \\
Brain/spinal cord & 198.3 \\
Retroperitoneum/peritoneum & 197.6 \\
Other digestive organs/spleen & 197.8 \\
Other urinary organs & 198.1 \\
Mediastinum & 197.1 \\
Kidney & 198.0 \\
Large intestine/rectum & 197.5 \\
Small intestine/duodenum & 197.4 \\
Ovary & 198.6 \\
\hline
\end{tabular}

